\title{
Community care: "the cascade of change"
}

\author{
Audit Commission to the rescue
}

Implementing the new community care legislation presents a daunting challenge to managers in both health and local authorities. Their agendas are already full, focused on other substantive changes. Health service managers are tackling the consequences of the separation between commissioners and providers of hospital services, family health services authorities are only just beginning to establish a clear management role, and social services managers are preoccupied with the heavy demands of the Children Act 1989 and Criminal Justice Act 1991.

The community care legislation requires authorities to rethink fundamentally their approach to planning: to shift decisions about the provision of services from those providing them to those using them and their carers. Readjustments are needed at every level, from authority members down to operational service providers, and furthermore, authorities must collaborate in planning and delivering services. All this would tax the ingenuity of most managers, and, unsurprisingly, only minimal progress has been made in most districts to weld authorities together across the public sector divide.

The Audit Commission's new report, Community Care: Managing the Cascade of Change, sets out the mechanisms that might promote collaboration between agencies. ${ }^{1}$ Of the high quality that we have come to expect of the commission, the report focuses on how these new arrangements might be set up. What is being demanded is the broaching of the solid wall that divides health from social services - not just at the level of senior management, which characterised the old joint planning system, but at all levels of the service. This would promote joint assessments of people's needs, joint planning of services at an operational level, coordination of the use of skilled and unskilled staff, and a unified strategic plan for using resources for health and social care in the community.

The Audit Commission's report is the first from a government agency to acknowledge that the new system will not necessarily be better than the old without the collaboration of the statutory agencies. "Any continuing failure of health and social authorities to work together will make more radical solutions increasingly unavoidable in the future," states the report. "If authorities wish to avoid further upheavals (as most do) the onus is on them to make the present arrangements work through active cooperation."
Just so; but how? The commission points to some successful examples of structural unification of local health and social services authorities in Norway, a federally funded project with similar aims in Arizona, and promising developments in Northern Ireland, where a single health and social services authority already exists. Currently in the rest of the United Kingdom consortium planning arrangements, in which budgets are pooled and true joint commissioning of care is planned, are in their infancy and confined to specific care groups-for example, people with learning disabilities or people who use mental health services. These have been restricted to those few authorities where trust has been established between agencies. The problems of creating a joint finance pool and a satisfactory system of financial accountability for using pooled budgets cannot be overstated. The creation of joint information systems has proved equally difficult.

Sadly, most authorities are nowhere near even considering such initiatives but are choosing instead to muddle along, collaborating to the minimum extent they find necessary. Doctors in acute hospitals have not yet understood the potentially disastrous consequences of this dilatory approach for their beds come next April. From that date no person requiring a publicly funded place in a residential or nursing home will move out of a hospital bed except by the decision of the local authority. Planning discharges is therefore likely to be the stick that drives health authorities and trusts to the planning table. Recognising this, the Audit Commission has chosen this as one of two topics to focus on in its auditing of collaborative arrangements between authorities. The other topic is the replacement of long stay hospitals for people with learning disabilities.

The commission's emphasis on monitoring interagency working should be warmly welcomed. Never before has an agency been charged specifically with this task, and as a result little has changed over the years. The commission's involvement should bring a considerable improvement in the planning of community care.

Professor of Psychogeriatrics,

ELAINE MURPHY

United Medical and Dental Schools of Guy's and/St Thomas's Hospitals, London SE1 9RT

1 Audit Commission. Community care: managing the cascade of change. London: HMSO, 1992
Many clinicians continue to believe that steroid drugs cause peptic ulcers. In reality the effects of these drugs on the gastroduodenal mucosa are far from clear cut; the evidence is fogged by conflicting data, many of them coming from many years ago.

Taking first the effects of steroids on the mucosa, experiments on animals have shown that they will induce mucosal lesions-but they also enhance the protection given to the gastric mucosa by prostaglandins and sulphydryls. ${ }^{1}$ They prevent gastrointestinal injury by platelet activating factor, and they accelerate the healing of lesions induced by alcohol and cysteamine. ${ }^{3}$ Steroids are known to inhibit the biosynthesis of cytoprotective prostaglandins-though this concept has been challenged recently ${ }^{45}-$ but they also suppress the production of leukotrienes, which are ulcerogenic.

Steroids seem to have a biphasic effect on gastric mucus: at first its secretion is enhanced (a finding in keeping with the 
inhibition of mucus after adrenalectomy), but then the mucus becomes depleted by impairment of the resynthesis of mucosubstances. ${ }^{6}$ Continuous administration of prednisone for several weeks reduces both adherent and soluble mucus. ${ }^{6}$ Steroids abolish the increase in gastric alkaline secretion in response to noxious stimuli ${ }^{7}$ but have no effect on duodenal secretion of bicarbonate. ${ }^{8}$

The effect of steroids on gastric acidity is again not straightforward, but they do seem to increase acid secretion; continuous administration leads to hypergastrinaemia due to G cell hyperplasia. ${ }^{9}$ In patients with peptic ulcers the amounts of circulating corticosteroids have been found to be either augmented or decreased, but stress ulcers in animals and humans are reduced by administration of steroids. ${ }^{10}$

Let us move on from this collection of conflicting data to the crunch question: Do steroids and corticotrophin induce peptic ulcers? The first attempt at a pooled analysis, by Conn and Blitzer in 1976, looked at 42 randomised studies and was inconclusive despite a trend in favour of an association between steroids and ulcers. ${ }^{11}$ They suggested that steroids increased the risk of a patient developing an ulcer only if they were taken for more than one month or in a cumulative dose exceeding the equivalent of $1000 \mathrm{mg}$ of prednisone. ${ }^{11} \mathrm{~A}$ later meta-analysis carried out in 1983 on 71 controlled trials detected a twofold increase in the risk of peptic ulcers during treatment with steroids. ${ }^{12}$

Unfortunately, both these analyses were handicapped by no prospective studies being available, the trials examined being designed for other purposes, and the criteria for diagnosing ulcers being quite variable and seldom reliable $-\mathrm{a}$ good number of the studies dated back to the era before endoscopy. Even the location (gastric or duodenal) of the ulcer craters was seldom specified. ${ }^{12}$

The pröblems have been clarified, however, by looking at subcategories. In experimental studies some glucocorticoids such as dexamethasone have seemed potentially more ulcerogenic than others, but no differences between the various steroid compounds have ever been reported in a clinical setting. On the other hand, some categories of patients (such as those with inflammatory bowel disease or skin disorders) seem to be relatively immune to steroid ulcers whereas patients with rheumatological disorders seem more susceptible. One explanation put forward when this observation was made was such patients' frequent use of both aspirin and steroids, aspirin being responsible for the occurrence of the ulcers and steroids for the inhibition of their repair..$^{13}$ Intake of non-steroidal anti-inflammatory drugs is known to have several adverse effects on the stomach, including a reduction in mucosal prostaglandins, impairment of secretion of mucus and bicarbonate, impairment of mucosal blood flow, increased production of leukotrienes and cytotoxic oxyradicals, and depletion of mucosal ATP. ${ }^{14}$
A recent large case-control study in the United States confirmed that patients taking steroids doubled their chance of developing a peptic ulcer but also showed that the risk was confined to patients concurrently receiving non-steroidal anti-inflammatory drugs (relative risk $4 \cdot 4$; $95 \%$ confidence interval $2 \cdot 0$ to $9 \cdot 7$ ). The gastric and duodenal mucosas were affected in the same way. Patients taking steroids but not taking non-steroidal anti-inflammatory drugs, by contrast, had an incidence of peptic ulcer similar to that in the control population. ${ }^{15}$

In the light of these data doctors who are in the habit of prescribing $\mathrm{H}_{2}$ receptor antagonists to every patient starting treatment with steroids should reconsider. The conclusion should surely be that prescribing both steroids and nonsteroidal drugs should be avoided whenever possible. If the combined treatment is given the high risk of peptic ulcer should be recognised. If it is thought wise to counteract the adverse effects of two drugs by giving a third the choice will be empirical since no controlled studies have been reported. The value of acid inhibitors is uncertain; on theoretical grounds the use of gastroprotective agents such as sucralfate or misoprostol seems more reasonable, but their value has yet to be proved.

M GUSLANDI Senior Registrar

A TITTOBELLO Professor of Medicine

Gastroenterology Unit, S Raffaele Hospital,

Milan,

Italy

I Szabo S, Gallagher T, Horner HC, Frankel PV, Underwood RH, Kontwoek SJ, et al. Role of adrenal cortex in gastric mucosal protection by prostaglandins, sulfhydryls and cimetidine in the rat. Gastroenterology 1983;85:1384-90.

Wallace JL, Whittle BJR. Gastrointestinal damage induced by platelet-activating factor. Inhibition by the corticoid dexamethasone. Dig Dis Sci 1988;33:225-32.

3 Szabo S, Vattai P, Morales RE, Saha B, Neumeyer JL, Lequesne PW. Effect of a new class of steroids on healing of experimental chronic duodenal ulcers. Gastroenterology 1991;100:A171

4 Kuroiwa M, Sugiyama S, Tsukamoto Y, Goto $\mathrm{H}$, Ohara A, Hosoino $\mathrm{H}$, et al. Effects of NSAID and steroids on ethanol-induced gastric lesions in rats: steroids are not noxious agents against gastric injury. Gastroenterolo $1991 ; 100: A 102$.

5 Wallace JL. Glucocorticoid-induced gastric mucosal damage: inhibition of leukotriene, but not prostaglandin biosynthesis. Prostaglandins 1987;34:311-6.

6 Guslandi M. Gastric mucus. In: Scarpignato C, Bianchi Porro G, eds. Clinical investigation of gastric function. Basle: Karger, 1990:103-26.

7 Nobuhara Y, Ueki S, Takeuchi K. Influence of prednisolone on gastric alkaline response in ra stomach. Dig Dis Sci 1985;30:1166-73.

8 Garner A, Heylinds JR, Hampson SE, Stanier AM. Pharmacological profile of duodenal alkalin secretion. Alimentary Pharmacology and Therapeutics 1990;4:465-76.

9 Delaney JP, Michel HM, Bonsack ME, Eisenberg MM, Dunn DH. Adrenal corticosteroids cause gastric cell hyperplasia. Gastroenterology 1978;76:913-6.

10 Szabo S. Biology of disease: pathogenesis of duodenal ulcer disease, Lab Invest 1984:51:121-47.

11 Conn Ho, Blitzer BL. Nonassociation of adrenocorticosteroid therapy and peptic ulcer N Engl f Med 1976:294:473-9.

12 Messer J, Retman D, Sacks HS, Smith H, Chalmers TC. Association of adrenocorticosteroid therapy and peptic ulcer disease. $N$ Engl $\mathcal{Y}$ Med 1983;309:21-4.

13 Spiro H. Is steroid ulcer a myth? N Engl f Med 1983;309:405-7.

14 Rainsford KD. Mechanisms of NSAID-induced gastron 7 . preventing ulceration and symptoms from these agents. Alimentary Pharmacology and Therapeutics 1988. 2(suppl 1):43-55.

15 Piper JM, Ray WA, Daughterty JR, Griffin MR. Corticosteroid use and peptic ulcer disease: role of nonsteroidal anti-inflammatory drugs. Ann Intern Med 1991;114:735-40. 